\title{
Possíveis relações entre o uso de fontes de informação e a competência em informação
}

\author{
Possible relationship between use of information \\ sources and information literacy
}

\author{
Marcos Aurélio GOMES' \\ Lígia Maria Moreira DUMONT²
}

\section{Resumo}

A apreensão da informação pelos indivíduos tem grande possibilidade de se realizar à medida que eles dominem as ações relacionadas à localização, ao acesso e ao uso das fontes de informação para a construção do conhecimento. Essas ações podem ser compreendidas como competência em informação. A partir do exposto, o objetivo deste artigo é discutir as possíveis interrelações entre o uso de fontes de informação e as competências em informação. Com base na pesquisa bibliográfica, investigaram-se as conexões existentes entre fontes, indústria e competência em informação. É discutido o papel das bibliotecas na efetivação do encontro entre as necessidades de informação dos usuários e as possíveis fontes de resposta. As reflexões obtidas indicam a atuação da indústria da informação na contemporaneidade, os desafios apontados pela tecnologia da informação como vetor dos fluxos informacionais, as questões relacionadas à competência e às fontes de informação como elo de desenvolvimento social e econômico, além da inserção de uma agenda de pesquisas para tal temática.

Palavras-chave: Competências em informação. Construção do conhecimento. Fontes de informação. Indústria da informação.

\begin{abstract}
Information acquisition by individuals can be obtained as far as these individuals can achieve and dominate the actions related to place, access and use of information sources to build up knowledge. These actions can be understood as information literacy. The aim of this article is to discuss the possible interrelations that can be established between the use of information sources and information literacy. Based on a bibliographical research it was possible to investigate the existing connections between sources, industry and information literacy. We discuss the role of libraries in meeting the information needs of users and the possible sources of response. We found that all these are responsible for information literacy: the contemporary information industries, challenges pointed out by information technology such as informational flow vector, issues related to literacy and information sources as a link of social and economic development, and the implementation of a research agenda for this topic.
\end{abstract}

Keywords: Information literacy. Construction of knowledge. Information sources. Information industry.

\section{Introdução}

mundo contemporâneo se constitui na perspectiva de que as informações são geradas para pos- sibilitar novos conhecimentos que, consequentemente, irão favorecer a tomada de decisões nos mais diversos contextos. Ainda como parte desse entendimento, as tecnologias são consideradas necessárias para contribuir

\footnotetext{
1 Universidade Federal de Alagoas, Instituto de Ciências Humanas, Comunicação e Artes, Curso de Biblioteconomia. Av. Lourival Melo Mota, s.n., Cidade Universitária, Campus A. C. Simões, 57072-900, Maceió, AL, Brasil. Correspondência para/Correspondence to: M.A. GOMES.E-mail:<marcosaureliog@gmail.com>.

2 Universidade Federal de Minas Gerais, Escola de Ciência da Informação, Departamento de Teoria e Gestão da Informação. Belo Horizonte, MG, Brasil. Recebido em 16/12/2013, reapresentado em 20/5/2014 e aceito para publicação em 7/7/2014.
} 
com o processo de organização, recuperação e transmissão da informação.

De fato, a tríplice aliança que se forma entre informação, conhecimento e tecnologia parece conformar uma sociedade na qual essa triangulação opera de forma interdependente para produzir produtos e serviços em quase todos os setores da atividade humana.

Nesse sentido, a apreensão da informação pelos indivíduos tem grande possibilidade de se realizar na medida em que eles possam dominar as ações relacionadas à localização, ao acesso e ao uso das fontes de informação em situações e contextos múltiplos. Tais ações podem ser compreendidas como competências em informação.

A partir daí, o debate que se trava concerne ao nexo intrínseco entre as fontes e a competência em informação. Pelo exposto, pode-se depreender que a satisfação da necessidade de informação encontra-se intrinsecamente relacionada às fontes, isto é, estas comportariam elementos inscritos com a possibilidade de o sujeito construir significados. Dessa forma, infere-se que a função das fontes seria reduzir incertezas e contribuir com a construção de novos saberes individuais e coletivos.

Mediante tais reflexões, o objetivo deste trabalho é discutir as possíveis inter-relações que se estabelecem entre as fontes e as competências em informação como eixo ou meio articulador para geração de conhecimento. Entretanto, não se pretende, neste trabalho, realizar uma discussão exaustiva, mas contribuir com um resgate de alguns elementos que possibilite subsidiar o entendimento da noção e da importância das fontes de informação e, dessa forma, elaborar possíveis considerações sobre esse tema, que mobiliza parte das discussões em Biblioteconomia e na Ciência da Informação, e que se reflete também na sociedade.

\section{Procedimentos metodológicos}

Compreende-se, conforme apontado por Ander-Egg (1978, p.28, grifo nosso), que a pesquisa é um "procedimento reflexivo sistemático, controlado e crítico, que permite descobrir novos fatos ou dados, relações ou leis, em qualquer campo do conhecimento". Essas relações foram fundamentais, neste trabalho, para permitir as conexões estabelecidas entre fontes, indústria e competência em informação.

Ante o exposto, a metodologia utilizada para atingir o objetivo proposto foi a pesquisa bibliográfica, considerando que"[...] o mais importante para quem faz opção pela pesquisa bibliográfica é ter a certeza de que as fontes a serem pesquisadas já são reconhecidamente do domínio científico"(Oliveira, 2007, p.69).

Buscou-se recuperar, em diversas fontes (artigos científicos, dicionários, manuais, livros, dissertações, teses e sites), um referencial para subsidiar um diálogo reflexivo entre as temáticas propostas neste artigo - fontes de informação, indústria da informação e competência em informação -, e, desse modo, assegurar a apreensão da realidade e a construção do conhecimento sobre essas temáticas.

\section{Fontes de informação}

O verbete apresentado por Cunha e Cavalcanti (2008, p.172) para a definição de fontes de informação as vincula a "[...] documentos que fornecem respostas específicas [...]", representando, assim, a essencialidade das experiências e vivências humanas, isto é, o conteúdo das representações sociais que comportam elementos científicos, tecnológicos, financeiros, econômicos, legais, políticos e, também, culturais, literários e artísticos. Mais adiante, esses autores acrescentam àquele verbete "Origem física da informação, ou lugar onde pode ser encontrada. Tanto pode ser uma pessoa, como uma instituição [...]" (p.172); logo, as fontes se inserem em determinados espaços institucionalizados (públicos ou privados). Nessa definição, os indivíduos também são considerados, pois podem possuir conhecimento especializado a ser compartilhado em determinadas situações (Choo, 2003).

No contexto organizacional, as fontes de informação parecem ser relevantes na medida em que os tomadores de decisão necessitem prospectar novos negócios e monitorar o ambiente tanto interno como externo. Nesse sentido, Choo (2003, p.99) observa que "[...] falhas ou deficiências de conhecimento ou compreensão podem ser expressas em perguntas ou tópicos 
colocados perante um sistema ou fonte de informação [...]". Em vista disso, considera-se que uma lacuna no conhecimento do indivíduo poderá ser resolvida mediante a possibilidade de acesso a uma possível fonte de informação.

Genericamente, as fontes de informação designariam "[...] todos os tipos de meios (suportes) que contêm informações suscetíveis de serem comunicadas" (Instituto de Tecnologia do Paraná, 1997, p.135). Nesses termos, pode-se considerar duas propriedades: i) a tangibilidade - registros organizados e sistematizados em determinado suporte; ii) a intangibilidade -, conhecimento tácito dos indivíduos em alguma área especifica (experts). As duas propriedades têm como finalidade a transmissão de algo a alguém (Buckland, 1991). Assim, as fontes de informação são veículos potenciais que podem possuir uma determinada informação para um determinado sujeito para satisfazer uma determinada necessidade.

A título de contextualização histórica, vale registrar que, no fim do século XIX, Meadows (1999) já constatava uma situação preocupante em relação ao crescimento e ao acesso à informação. Para Meadows o aumento da informação gerou dificuldades de acesso, e o desenvolvimento de instrumentos (resumos e índices) buscava facilitar a recuperação e, posteriormente, o uso dos materiais informacionais. Desse modo, entende-se que, na medida em que crescem os periódicos primários, surgem instrumentos secundários para facilitar o acesso dos pesquisadores à literatura primária. O Chemical Abstracts é um exemplo de fonte de informação orientada aos pesquisadores, que se desenvolveu conforme as necessidades dos pesquisadores desse grupo e que, ao mesmo tempo, foi visto por seus idealizadores como uma oportunidade de negócio no mercado a ser desenvolvido. O Biological Abstract, Engineering Index e o Index Medicus são outros exemplos que me-recem destaque.

As fontes - tipificadas em primárias, secundárias e terciárias -, caracterizam-se por suas especificidades (Quadro 1) quanto ao conteúdo e à abrangência, fornecendo informações que "[...] quando adequadamente assimiladas, produzem conhecimento, modificam o estoque mental de informações do indivíduo e trazem benefícios ao seu desenvolvimento e ao desenvolvimento da sociedade em que ele vive" (Barreto, 1994, online).

Mesmo com o advento e amplo uso da Internet, as mesmas três tipificações das fontes de informação ainda não se alteraram completamente, subsistem independentemente do suporte informacional, seja ele digital ou físico. Todavia, acredita-se que é apenas uma questão de tempo para que o formato eletrônico prevaleça sobre o impresso (Silva \& Tomaél, 2004).

Em decorrência do volume crescente de informações disponibilizadas (quantidade $X$ qualidade) pela Internet, Tomaél et al. (2008) alertam que tanto no contexto acadêmico como no profissional os indivíduos devem possuir critérios para avaliar a informação recuperada pela rede.

Nessa mesma direção, saber selecionar e avaliar a qualidade das fontes de informação na Web está relacionado à competência dos indivíduos para usar e, consequentemente, incorporar a nova informação ao conhecimento existente.

Quadro 1. Classificação das fontes de informação.

\begin{tabular}{|c|c|c|}
\hline Fontes primárias & Fontes secundárias & Fontes terciárias \\
\hline $\begin{array}{l}\text { Definição: [...] aquelas que contêm informações } \\
\text { originais ou, pelo menos, novas interpretações } \\
\text { de fatos ou idéias já conhecidos (p.20). }\end{array}$ & $\begin{array}{l}\text { Definição: [...] facilitar o uso do conhecimento } \\
\text { disperso nas fontes primárias. [...] apresentam } \\
\text { a informação filtrada e organizada de acordo } \\
\text { com um arranjo definido, dependendo da } \\
\text { finalidade da obra (p.20). }\end{array}$ & $\begin{array}{l}\text { Definição: [...] aquelas que têm a função } \\
\text { de guiar o usuário da informação para as } \\
\text { fontes primárias ou secundárias (p.20). }\end{array}$ \\
\hline $\begin{array}{l}\text { Exemplos: Congressos e Conferências, Literatura } \\
\text { Comercial, Normas Técnicas, Patentes, Artigos } \\
\text { de Periódicos, Relatórios Científicos e Técnicos, } \\
\text { Teses e Dissertações. }\end{array}$ & $\begin{array}{l}\text { Exemplos: Dicionários, Tabelas, Enciclopédias, } \\
\text { Revisões de Literatura, Tratados, Livros Textos, } \\
\text { Manuais e Anuários. }\end{array}$ & $\begin{array}{l}\text { Exemplos: Bibliografia de bibliografia, } \\
\text { Guias Bibliográficos, Periódicos de In- } \\
\text { dexação, Catálogos Coletivos, Diretórios } \\
\text { e Resumos. }\end{array}$ \\
\hline
\end{tabular}

Fonte: Campello e Campos (1993). Elaborado pelos autores (2014). 
Tomaél et al. (2008), com base nos resultados de pesquisa realizada em 2004, propõem seis indicadores com 29 critérios para a avaliação de fontes de informação disponíveis por meio da Internet (Quadro 2). Os autores alertam para a necessidade de se considerarem tais atributos ao serem utilizadas as reais necessidades de informação dos usuários e de rigor quanto às especificidades das fontes a serem avaliadas.

Tais indicadores e critérios representam desafios e oportunidades para os profissionais da informação, pois se caracterizam como possíveis ofertas de negócios (serviços e produtos) e relações mediante a concepção de biblioteca, que, conforme Belluzzo (2010, p.40), configura-se como "[...] organização prestadora de serviços à sociedade". Desse modo, na perspectiva da oferta de serviços de informação, tais profissionais poderiam capacitar os indivíduos para avaliação e uso das fontes de informação no ambiente Web. Com essa possibilidade, Belluzzo aduz que possuir competência em informação consiste, entre outros aspectos, em avaliar criticamente a informação (pertinência e relevância) acessada a partir das necessidades de informação. Assim sendo, esses profissionais estariam colaborando para o desenvolvimento de habilidades específicas relacionadas ao acesso e ao uso da informação.

Entende-se que a existência de fontes de informação e o seu uso eficaz são essenciais para o desenvolvimento dos países (Lastres \& Ferraz, 1999). Dessa maneira, tem-se que as fontes de informação, ao serem localizadas, acessadas, avaliadas e utilizadas, são rele- vantes para a construção do conhecimento, possibilitando, assim, as ações de diversos atores sociais. Logo, as bibliotecas, arquivos, centros de informação/documentação ou Internet representam uma parte de uma estrutura maior que contribui para a indústria da informação como um todo. Exercem papel fundamental na sociedade, com atividades relacionadas à coleta, à organização e à disponibilização de inúmeras fontes de informação.

\section{Indústria da informação}

A partir da ideia de que se conformam em estruturas (impressas ou eletrônicas), as fontes são produtos inerentes a uma indústria, denominada de indústria da informação, que possui, por sua vez, forte base tecnológica, pois objetiva

[...] criar e distribuir produtos, serviços e sistemas de informação principalmente em formatos digitais. [...] fornecem produtos e serviços de informação, utilizando novas tecnologias e agregando valor ao material, permitindo o manejo inovador das informações (Campello, 2003, p.30).

Essa indústria tem, nos países desenvolvidos, os principais produtores de informação (Barreto, 1994; Valentim, 2002; Le Coadic, 2004). Nesse cenário, é interessante observar que, segundo Valentim (2002), a indústria da informação teve início nos Estados Unidos. Por seu turno, Campello (2003) acrescenta que, em 1968,

Quadro 2. Parâmetros para avaliar fontes de informação na Internet.

\section{Indicadores}

Arquitetura da informação - estrutura detalhada (modelo) de recursos de informação digital para navegação e busca.

Aspectos intrínsecos - qualidade do conteúdo $\mathrm{X}$ necessidade do usuário.

Aspectos de compartilhamento - cooperação/interação do usuário/ produtor de informação.

Fonte: Tomaél et al. (2008). Elaborado pelos autores (2014).

\section{Critérios}

Mídias; acessibilidade; usabilidade; organização (do conteúdo); navegação; rotulagem; busca; segurança e interoperabilidade.

Precisão; facilidade de compreensão; objetividade; consistência e relevância; atualização; integridade e alcance.

Autoridade e responsabilidade.

Conveniência; estabilidade; adequação; facilidade de manuseio.

Formato; adequação da representação do assunto; clareza da definição e precisão de domínios; e representação concisa e consistente.

Arquitetura de participação; produtor e consumidor; e folksonomia. 
foi fundada uma associação, denominada de Information Industries Association, para representar esse novo segmento.

Tendo isso em vista, compreende-se que o desenvolvimento das redes cooperativas foi um dos grandes passos para a indústria da informação; Valentim (2002) cita o Medical Literature Analysis and Retrieval System (Medlars) como modelo. Tais redes tinham como objetivo, inicialmente, processar e disseminar informação científica em uma área específica do conhecimento no âmbito daquele país. Posteriormente, foram estabelecidas políticas para sistematizar e compartilhar informações entre as instituições estadunidenses (Valentim, 2002). A autora salienta que

A iniciativa americana foi tão eficiente que não fomentou somente acordos cooperativos nacionais, mas, também, acordos cooperativos internacionais, uma vez que outros países se interessaram em participar dessas redes, ampliando, assim, a consolidação e o processamento de informações especializadas e, de forma competente, fez com que essas redes cooperativas nacionais passassem a ser internacionais, em detrimento de várias diferenças como: língua, cultura, competitividade entre si etc. (Valentim, 2002, p.23).

A partir daí, com o advento da informática, novos produtos e serviços relacionados à informação e, consequentemente, novas formas de acesso foram desenvolvidos, como os serviços online (ex:: MedLine); posteriormente, os sistemas de informação ou bancos de dados comerciais (ex.: Dialog); em seguida, a tecnologia óptica (CD-ROM); e, atualmente, via rede Internet. Essas novas formas se disseminaram ao redor do mundo, impactando as estruturas macrossociais (infraestrutura, econômica, educacional, política, ciência e tecnologia e organizacional) entre as economias.

Nessa perspectiva, os países desenvolvidos são produtores e detentores potenciais de informação e tecnologia. Sendo assim, possivelmente existe sujeição entre produtor versus usuário nos domínios da informação.

Quanto à dependência existente entre os países desenvolvidos e em desenvolvimento, ela é real, pois, nos últimos, há investimentos superiores em Pesquisa e Desenvolvimento (P\&D). Inclusive, a pesquisa realizada por
Mangue (2007) demonstra de forma inequívoca tal subordinação, ao estudar, empiricamente, o processo de informatização em três sistemas de bibliotecas universitárias na África do Sul, no Brasil e em Moçambique.

Em relação à situação de dependência, vale frisar que ela não é apenas financeira [...]. Ela é também tecnológica. Neste caso, a transferência tecnológica não se faz acompanhar pela transferência de conhecimentos, mas, sim, e como agravante, pelos padrões de consumo e de investimentos tecnológicos dos países fornecedores: são as necessidades derivadas, uma vez que certo padrão de tecnologia vai demandar certo nível de qualificação, certo tipo de equipamentos, etc. (Mangue, 2007, p.271)

Assim, a tecnologia desenvolvida na maioria dos países desenvolvidos gera a eles mais conhecimento, emprego e renda.

Por sua vez, o Brasil, apesar de apresentar uma taxa evolutiva anualmente em P\&D, encontra-se em último lugar se for comparado a países emergentes, como Rússia e China (Tabela 1), conforme o Ministério da Ciência, Tecnologia e Inovação (MCT\&l) (Brasil, 2014).

Belluzzo (2010) argumenta que, para maior competitividade das organizações, é necessário que se faça duplo investimento: em P\&D e em educação. Para a autora, de nada adianta a disponibilização dos mais diversos aparatos tecnológicos sem indivíduos capacitados para utilizá-los devidamente.

Esses investimentos correspondem às estratégias fomentadas no país visando à geração de conhecimento, que se explicita por meio de fontes de informação (artigos, patentes, entre outros) nos mais diversos segmentos.

Na mesma tabela, encontra-se a posição do país no cenário mundial quanto aos indicadores de produção científica. Eles subsidiam os diversos segmentos nas tomadas de decisão, refletindo no desenvolvimento econômico e social e, de certa forma, na indústria da informação.

O trabalho de Valentim (2002) tem relevantes contribuições para a reflexão quanto aos aspectos de formação de políticas para o fortalecimento da indústria da informação no contexto nacional, considerando-se, para tanto, as informações que são geradas nos mais diversos setores econômicos. 
Tabela 1. Indicadores comparativos entre países selecionados.

\begin{tabular}{|c|c|c|c|c|c|}
\hline \multirow{2}{*}{ Países } & \multicolumn{2}{|c|}{ Dispêndios em P\&D (Bilhões de US\$) } & \multirow{2}{*}{ Artigos indexados Scopus - 2012} & \multicolumn{2}{|c|}{ Patentes de invenção - 2012} \\
\hline & 2001 & 2011 & & Pedidos & Concedidos \\
\hline África do Sul & 2,3 & - & 12766 & 318 & 142 \\
\hline Alemanha & 54,4 & 93,1 & 132505 & 29195 & 13835 \\
\hline Brasil & 13,2 & 27,6 & 53083 & 679 & 196 \\
\hline Canadá & 19,0 & 24,3 & 79017 & 13560 & 5775 \\
\hline China & 31,7 & 208,2 & 383117 & 13273 & 4637 \\
\hline EUA & 278,2 & 415,2 & 493337 & 268782 & 121026 \\
\hline França & 35,8 & 51,9 & 95534 & 11047 & 5386 \\
\hline Índia & - & - & - & 5663 & 1691 \\
\hline Itália & 16,8 & 24,8 & 77747 & 4516 & 2120 \\
\hline Japão & 103,7 & 146,5 & 111893 & 88686 & 50677 \\
\hline Reino Unido & 29,2 & 39,6 & 137413 & 12457 & 5213 \\
\hline Rússia & 12,6 & 35,0 & 37568 & 888 & 331 \\
\hline
\end{tabular}

Fonte: Brasil (2014). Elaborado pelos autores (2014).

Nota: P\&D: Pesquisa e Desenvolvimento.

Assim, Valentim (2002) atenta para as seguintes ações que poderiam subsidiar a indústria da informação:

- tratar tecnicamente as informações;

- promover a existência dessas informações à sociedade;

- disponibilizar essas informações gratuitamente ou comercialmente;

- fomentar o acesso a essas informações;

- aumentar a participação, principalmente da iniciativa privada, além da pública, no âmbito da indústria da informação.

Observa ainda que as novas informações ao processo produtivo geradas pelas grandes corporações podem ser estratégicas e confidenciais e, dessa forma, não podem ser divulgadas.

Por meio de tais colocações, evidencia-se que"[...] a economia de um país, portanto, está apoiada pela geração e pelo uso de informações/conhecimento. Esse é o diferencial [...]" (Valentim, 2002, p.32). Logo, estabelecer as bases para uma indústria da informação é traçar estratégias para o desenvolvimento nos mais diversos segmentos da atividade econômica, tornando as organizações mais competitivas.

Nas economias mais avançadas, a indústria da informação torna-se essencial devido ao acelerado desenvolvimento tecnológico - principalmente pelos produtos e serviços digitais disponibilizados pela Internet.
Nesse aspecto, a indústria da informação encontra-se estruturada, conforme a Organização para a Cooperação e Desenvolvimento Econômico, por estabelecimentos que se encontram envolvidos na produção e nos meios para transmissão e distribuição de informação e de produtos culturais, como também de dados ou de comunicações, e por aqueles encarregados por processamento de dados (Organization for Economic Co-operation and Development, 2013).

O Bureau of Labor Statistics (United States, 2014) dos Estados Unidos inclui as bibliotecas e os arquivos como parte do segmento do setor de informação uma vez que armazenam, fornecem e disponibilizam acesso à informação, pesquisa e recuperação de informações em meios impressos ou eletrônicos para os mais diversos segmentos sociais.

Nesse sentido, Valentim (2002) estabelece uma perspectiva para a indústria da informação no Brasil, considerando as interligações entre: (i) insumo básico é a informação e o conhecimento gerado (científico, tecnológico, de mercado e técnico), que são essenciais, pois impulsionarão a cadeia produtiva da indústria da informação; (ii) instituições - são as que estocam e institucionalizam os estoques de dados/informações (fontes de informação); (iii) estrutura - os meios pelos quais os dados/informação serão estocados e disseminados. Em face disso, são identificadas as conexões que possibilitam compreender os elementos ordenados e relacionados entre si de forma a permitir um provável desenvolvi- 
mento da indústria da informação, tendo na base as políticas de informação que emanam da ciência, da tecnologia e da indústria.

Historicamente, o ideário de disponibilizar a massa informacional poderia ser efetivado pela concepção do controle bibliográfico, sendo este entendido como o domínio sobre a massa informacional (Campello \& Magalhães, 1997). Vale ressaltar que Shera (1975) propôs uma perspectiva sociológica para o controle bibliográfico, isto é, vários atores sociais (governo, organizações e instituições) participariam do esforço de controlar e de disponibilizar a massa informacional de acordo com a demanda e as especificidades. Ações nesse sentido são realizadas, entretanto há interesses financeiros na geração e distribuição da informação. Desse modo, a informação torna-se mercadoria e, como tal, segue as regras do mercado.

A todos esses indícios subjazem as questões relacionadas às habilidades informacionais, isto é, as competências em informação que diversos segmentos da sociedade devem dominar.

\section{Competência em informação}

A partir da literatura, tem-se que, nas últimas décadas, mudanças foram percebidas tanto do ponto de vista teórico como, também, do empírico, no mundo, em relação à reestruturação produtiva e, consequentemente, novas regras foram impostas ao mundo do trabalho.

Com esse cenário, os indivíduos e as organizações, inclusive as bibliotecas e os serviços de informação, enfrentam alterações que estão localizadas nas inovações tecnológicas, na globalização da economia, nos novos modelos de gestão, na concepção de desenvolvimento sustentado e na flexibilização da produção e do trabalho. A partir desse contexto, desenvolve-se um processo de alteração na materialidade no âmbito das relações socioculturais, políticas e econômicas.

Belluzzo (2010) alerta que, se as bibliotecas e os serviços de informação não quiserem se tornar obsoletos e passíveis de serem substituídos, eles devem se tornar cada vez mais competentes e qualificados perante os desafios impostos pela sociedade contemporânea. No âmbito das bibliotecas e dos serviços de informação, acredita-se que a construção de formas de gestão centradas no indivíduo e por competências possibilite a competitividade, pois é reconhecer o potencial estratégico de negócios na prestação e oferta de serviços e produtos à sociedade, intensificando, desse modo, a presença como segmento da indústria da informação.

Novas questões são postas à sociedade contemporânea, dentre as quais, a noção de competência. Para Zarifian (2003), tal noção vai tomando forma à medida que as organizações necessitam reconhecer as competências dos indivíduos independentemente dos postos de trabalho para ações práticas.

O autor acrescenta que a competência é "[...] uma inteligência prática das situações, que se apoia em conhecimentos adquiridos e os transforma à medida que a diversidade das situações aumenta" (Zarifian, 2003, p.137). Assim, não são somente os recursos obtidos pelos indivíduos, mas, principalmente, os colocados em ação.

Zarifian (2003) entende que não se deve travar embates entre as noções de qualificação e competências. Para o autor, a competência se traduz em uma nova maneira de qualificação. A noção de competência se amplia para além de uma qualificação circunscrita à qualificação do trabalhador (saber fazer) versus a qualificação do trabalho (requerida pela organização). Acrescenta, ainda, que as competências dos indivíduos são construídas considerando a multiplicidade de fontes de conhecimento, especialidades e experiências. Consequentemente, uma integração de saberes na resolução de problemas nessa nova economia.

Em vista disso, há uma reconfiguração entre as economias, pela qual a distinção entre países ricos e pobres não é instituída somente pelo nível de industrialização, mas sim estabelecida pela produção de informação, pela capacidade de aprendizado e pelo uso dessa informação para a geração de conhecimentos (Lastres \& Ferraz, 1999). Pode-se então falar sobre a dimensão de uma competência específica: a competência em informação.

Diante do exposto, observa-se que o movimento da competência em informação pode ter suas raízes nas modificações sociais advindas de uma forte reestruturação dos meios de produção, o que implicaria que a origem da noção de competência em informação encontra-se relacionada à indústria da informação. 
Nos anos de 1970, Paul G. Zurkowski, que ocupava o cargo de Presidente da Information Industries Association e era membro da Comissão Nacional de Bibliotecas e Ciência da Informação dos Estados Unidos, afirmava que

[...] o governo norte-americano se preocupasse em garantir que a população do país desenvolvesse competência informacional que Ihe permitisse utilizar a variedade de produtos informacionais disponíveis no mercado (Campello, 2003, p.30).

Nessa direção, infere-se o objetivo de promover uma indústria e, ao mesmo tempo, criar ou estimular um mercado consumidor para os diversos artefatos tecnológicos que começavam a surgir.

É preciso considerar, também, que todos esses fatores ocorreram em paralelo à emergência da sociedade da informação e outros aspectos conjunturais que marcaram a década de 1970 (crise do petróleo, recessão americana, fim da guerra do Vietnã, crescimento da economia japonesa).

A propósito, Daniel Bell foi um dos principais representantes teóricos que, nos anos 1970, defendia o conhecimento como recurso e, também, o uso das tecnologias da informação nos mais diversos segmentos da sociedade. Forma-se, assim, a ideia de uma nova sociedade pós-industrial (Kumar, 1997). Para Kumar (1997, p.15) essa "[...] nova sociedade é [...] definida e rotulada por seus novos métodos de acessar, processar e distribuir informação".

Naquele contexto, a "[...] competência informacional foi a bandeira erguida pela classe bibliotecária americana [...] para as mudanças demandadas pela sociedade da informação [...]" (Campello, 2003, p.32).

Tais discussões ficaram, a princípio, restritas aos Estados Unidos, tornando-se, posteriormente, agenda de pesquisa de vários países. No Brasil, essa temática foi abordada, primeiramente, por Caregnato (2000). A partir daí, diversos estudos vêm sendo desenvolvidos por pesquisadores da área da Biblioteconomia e da Ciência da Informação, inclusive, adquirindo status de disciplina em alguns Programas de Pós-Graduação (stricto sensu), conforme constatado por Oliveira (2011).

Vale citar que a American Library Association foi a grande responsável por promover e incentivar tal debate.
É inegável que ainda se buscam a consolidação teórica e padronização terminológica em torno dessa temática (Dudziak, 2001; Campello, 2003; Hatschbach \& Olinto, 2008; Campello, 2009; Belluzzo 2010; Gasque, 2010). Mesmo assim, o que se observa é a possibilidade de construção de um novo paradigma para as bibliotecas, para os profissionais da área e para os usuários.

Diante de tais considerações, Hatschbach e Olinto (2008) apresentam uma trajetória histórica que possibilitou constatar que a noção de competência em informação vem sofrendo alterações ao longo do tempo, em conformidade com as questões sociais. Tal trajetória inicia-se pelo resgate do movimento da instrução bibliográfica e pelo modelo de aprendizagem por meio do processo de busca e pelo uso da informação como prática disciplinada de pesquisa e, posteriormente, com o uso das teorias cognitivista e construtivista na aprendizagem. A partir daí a compreensão da competência em informação não se encontra somente relacionada a programas de ensino, ainda que no Brasil não se vivencie completamente essa realidade, como também em atividades e espaços profissionais; ela perpassa pela elaboração de material instrucional e pelas tecnologias para a aprendizagem, além das abordagens sociais (inclusão, cidadania e alfabetização digital), principalmente, em países em desenvolvimento.

Nessa perspectiva, potencializam-se as questões relacionadas à necessidade, localização, acesso/recuperação, uso e comunicação da informação em diversos espaços, pois a competência em informação pretende possibilitar o aprender a aprender por meio da informação (Belluzzo, 2010), seja em ambiente tradicional, seja em plataforma digital. Em outras palavras, possibilita a construção de novos conhecimentos.

A biblioteca, por sua vez, pode contribuir e tornar-se um local de aprendizagem por meio dos mais variados materiais informacionais. Para Belluzzo (2010), é essencial que as bibliotecas e serviços de informação criem facilidades de acesso e uso, como também que se agreguem valor e customização aos produtos e serviços.

Nesse sentido, Loerstcher e Woolls (2005) intensificam esse debate quando posicionam a necessidade de a biblioteca e/ou os profissionais da informação se 
envolverem no desenvolvimento de produtos/serviços com ações específicas e com foco nos usuários. Os autores citam como exemplo o uso da tecnologia da informação na arquitetura de tutoriais e folhetos eletrônicos e acrescentam o envolvimento desses profissionais com as práticas pedagógicas. Chamam a atenção para que os bibliotecários, mediante o excesso de fontes de informação (impressas e digitais), tomem uma posição de liderança, devendo se especializar cada vez mais em competência em informação, para em seguida capacitar os usuários na busca e uso dessas fontes.

O entendimento por parte dos indivíduos sobre fontes torna-se essencial para que eles possam utilizá-las a fim de satisfazerem suas necessidades de informação em quaisquer que sejam suas atividades. Inclusive, Campello (2009) e Santos et al. (2008) corroboram essa assertiva.

Nesse sentido, Campello (2009), ao discutir o estudo de Doyle (1992), afirma que o sujeito torna-se competente em informação quando é capaz de:

1. Reconhecer a necessidade de informação; 2. Reconhecer que informações acuradas e completas são a base para a tomada de decisões inteligentes;

3. Formular questões baseadas na necessidade de informação;

\section{Identificar fontes de informação potenciais;}

5. Desenvolver estratégias de busca adequadas;

6. Acessar fontes de informação inclusive as eletrônicas;

\section{Avaliar informações;}

8. Organizar informações para aplicações práticas;

9. Integrar novas informações ao corpo de conhecimento existente;

10. Usar informações para pensar criticamente e para solucionar problemas (Campello, 2009, p.75, grifo nosso).

Já Santos et al. (2008, p. 218) expõem, claramente, que a competência em informação "[...] habilita os indivíduos para lidar com todas as fontes de informação, no sentido de organizar, filtrar e selecionar o que realmente é importante para a tomada de decisão [...]"
O plágio e a propriedade intelectual são questões levantadas por Hatschbach e Olinto (2008) na avaliação das competências em informação, pois implicam aspectos de ética e valores com relação ao uso apropriado das fontes de informação. Nesse sentido, quando se referencia adequadamente as fontes de informação utilizadas, colabora-se com a comunicação científica e, desse modo, evita-se a violação dos direitos autorais.

A partir dessas discussões, entende-se a competência em informação como o domínio consciente e atitudinal do indivíduo, no qual estão envolvidos elementos cognitivos, físicos, operacionais e éticos relacionados à informação. Depreende-se que a aquisição da competência em informação é um movimento que envolve múltiplos atores de diversas áreas do conhecimento, socialmente construído em situações históricas, desse modo, possibilitando o deslocamento da dimensão conceitual para as práticas educacionais, científicas e profissionais (Hatschbach \& Olinto, 2008; Campello, 2009; Belluzzo, 2010). De certa forma, esse movimento poderá refletir em alguns dos indicadores de desenvolvimento apresentados anteriormente na Tabela 1.

Tal compreensão se dá porque diversos autores acreditam que há necessidade de uma educação para a informação, destacando-se Le Coadic (2004, p.114), que considera que os indivíduos necessitam "[...] aprender a se informar e aprender a informar, e sobre onde adquiri-las [...]". Trata-se, portanto, de um processo que envolve busca, acesso, localização, avaliação, construção e comunicação da informação na e para a sociedade.

\section{Conclusão}

De fato, a sociedade da informação trouxe novos desafios e possibilidades à contemporaneidade. Um exemplo disso é que a tecnologia da informação tem transformado, de forma surpreendente, a maneira como se localiza, acessa, usa, recebe e transmite a informação; contudo, somente a tecnologia não basta. O grande desafio é interagir com o fluxo informacional, que é dinâmico. Dessa forma, adquirir competência em informação é possuir um diferencial, pois a competência em informação é uma exigência na atual sociedade, marcada pela competitividade entre países, organizações e indivíduos. Questões como necessidade, acesso, localização e uso 
da informação são cruciais para quaisquer sociedades, principalmente para aquelas nas quais a indústria da informação não se encontra de forma consolidada.

Quanto às fontes de informação, é inexorável que são relevantes, pois, nelas, encontra-se aquilo que pode subsidiar as ações e decisões dos indivíduos e grupos em quaisquer situações e se constituem como resultados dos avanços científicos e tecnológicos.

Outro desafio: a tecnologia vem permitindo um trabalho significativo de digitalização de acervos de bibliotecas e arquivos. Porém, tal tecnologia está nas mãos de grandes empresas privadas que anteviram esse mercado promissor. As empresas têm por objetivo dar lucro a seus acionistas, em contraponto aos objetivos da Ciência da Informação, que é oferecer conhecimento ao público. Certamente o conhecimento não pode ser retido só pela visão do lucro. O fato de os direitos autorais estarem detidos pelas empresas configura uma situação de monopólio da informação.

As bibliotecas estão buscando respostas para essa questão, mas não se trata de um trabalho fácil. Uma das alternativas utilizadas é buscar satisfazer as necessidades das comunidades por elas atendidas, por meio de programas de educação de usuário. Todavia, o caminho ainda não foi totalmente decifrado e a própria noção de competência em informação incorpora outros elementos, como aspectos cognitivos e comunicacionais.

\section{Referências}

Ander-Egg, E. Introdución a las técnicas de investigación social: para trabajadores sociales. 7.ed. Buenos Aires: Humanitas, 1978.

Barreto, A.A. A questão da informação. Revista São Paulo em Perspectiva, v.8, n.4, 1994. Disponível em: <http://www. seade.gov.br/produtos/spp/v08n04/v08n04_01.pdf>. Acesso em: 10 maio 2014.

Belluzzo, R.C.B. Competências e novas condutas de gestão: diferenciais de bibliotecas e sistemas de informação. In: Valentim, M.L.P. (Org.). Ambientes e fluxos de informação. São Paulo: Cultura Acadêmica, 2010. p.23-54.

Brasil. Ministério de Ciência e Tecnologia e Inovação. Indicadores nacionais de ciência, tecnologia e inovação. Brasília: MCTI, 2014. Disponível em: <http://www.mct.gov.br/ index.php/content/view/740.html?execview>. Acesso em: 5 maio 2014.

Buckland, M.K. Information as thing. Journal of American Society for Information Science, v.42, n.5, p.351-360, 1991.
Entretanto, a sociedade ainda não (re)conhece a biblioteca como espaço social, tampouco como espaço de aprendizagem. Assim, vários desafios estão colocados, principalmente com a maciça utilização da informática na divulgação de informações e novas formas de gestão nas bibliotecas e serviços de informação.

Ademais, a interatividade hoje possível com os mais diversos arquivos eletrônicos permite uma atuação direta do usuário da informação, independente nos seus processos de busca da informação. Como não mais depende de intermediários para acessar fontes de informação, pode estabelecer um diálogo diferenciado e de seu interesse, sem intervenção dos bibliotecários de referência, por exemplo. Obtém sua informação de maneira subjetiva, individualizada, por suas preferências, independentemente dos serviços usuais prestados por unidades de informação.

Tendo em vista essas novas situações que se configuram na contemporaneidade, compreende-se que temas como política, cultura e regime informacional devem fazer parte de uma agenda constante de pesquisa de fontes de informação e competência em informação e também de reivindicações dos mais diversos segmentos ligados à área da informação, pois intrinsecamente a essas questões encontram-se as competências a serem adquiridas pelos atores sociais.

Campello, B. O movimento da competência informacional: uma perspectiva para o letramento informacional. Ciência da Informação, v.32, n.3, p.28-37, 2003. Disponível em: <http:// revista.ibict.br/ciinf/index.php/ciinf/article/view/26/22>. Acesso em: 10 maio 2014.

Campello, B. Letramento informacional: função educativa do bibliotecário na escola. Belo Horizonte: Autêntica, 2009.

Campello, B.; Campos, C.M. Fontes de informação especializada: características e utilização. 2.ed. Belo Horizonte: Editora UFMG, 1993.

Campello, B.; Magalhães, M.H.A. Introdução ao controle bibliográfico. Brasília: Briquet de Lemos, 1997.

Caregnato, S.E. O desenvolvimento de habilidades informacionais: o papel das bibliotecas universitárias no contexto da informação digital em rede. Revista de Biblioteconomia \& Comunicação, v.8, p.47-55, 2000.

Choo, C.W. A organização do conhecimento: como as organizações usam a informação para criar significado, construir conhecimento e tomar decisões. São Paulo: Senac, 2003. 
Cunha, M.B.; Cavalcanti, C.R.O. Dicionário de biblioteconomiae arquivologia. Brasília: Briquet de Lemos, 2008.

Doyle, C. Outcome measures for information literacy within the national education goals of 1990: Final report of the National Forum on Information Literacy. Summary of findings. Washington: US Department of Education, 1992.

Dudziak, E.A. A information literacy e o papel educacional das bibliotecas. 2001. Dissertação (Mestrado em Ciências da Comunicação) - Escola de Comunicações e Artes, Universidade de São Paulo, São Paulo, 2001.

Gasque, K.C.G.D. Arcabouço conceitual do letramento informacional. Ciência da Informação, v.39, n.3, p.83-92, 2010. Disponível em: <http://revista.ibict.br/ciinf/index.php/ciinf/ article/view/1819/1388>. Acesso em: 10 maio 2014.

Hatschbach, M.H.L.; Olinto, G. Competência em informação: caminhos percorridos e novas trilhas. Revista Brasileira de Biblioteconomia e Documentação, v.4, n.1, p.20-34, 2008. Disponível em: <http://rbbd.febab.org.br/rbbd/article/view/ 64>. Acesso em: 10 maio 2014.

Instituto de Tecnologia do Paraná. Manual de gestão de serviços de informação. Curitiba: Tecpar, 1997.

Kumar, K. Da sociedade pós-industrial à pós-moderna: novas teorias sobre o mundo contemporâneo. Rio de Janeiro: Jorge Zahar, 1997.

Lastres, H.M.M.; Ferraz, J.C. Economia da informação, do conhecimento e do aprendizado. In: Lastres, H.M.M.; Albagli, S. (Org.). Informação e globalização na era do conhecimento. Rio de Janeiro: Campus, 1999. p.27-57.

Le Coadic, Y. A ciência da informação. 2.ed. Brasília: Briquet de Lemos, 2004.

Loerstcher, D.V.; Woolls, B. Competência em informação: ajudando bibliotecários a aplicar a pesquisa no ensino da habilitação básica em obtenção de informação pelos usuários - a importância da interface humana. In: Passos, R.; Santos, G.C. (Org.). Competência e habilidades em informação na sociedade da aprendizagem. 2.ed. Bauru: Kairós, 2005. p.55-66.

Mangue, M.V. Consolidação do processo de informatização em sistemas de bibliotecas universitárias da África do Sul, Brasil e Moçambique. 2007. Tese (Doutorado em Ciência da Informação) - Escola de Ciência da Informação, Universidade Federal de Minas, Belo Horizonte, 2007.
Meadows, A.J. A comunicação científica. Brasília: Briquet de Lemos, 1999.

The Organization for Economic Co-operation and Development. OECD Science, Technology and Industry Scoreboard 2013. OECD Publishing, 2013. Available from: <http://dx.doi.org/10.1787/sti_scoreboard-2013-en>. Cited: May 8, 2014.

Oliveira, D.A. A influência da Ciência da Informação nos cursos de graduação em Biblioteconomia no Brasil: formação docente, aspectos teóricos e manifestações temáticas. 2011. Tese (Doutorado em Ciência da Informação) - Escola de Ciência da Informação, Universidade Federal de Minas Gerais, Belo Horizonte, 2011.

Oliveira, M.M. Como fazer pesquisa qualitativa.Petrópolis: Vozes, 2007.

Santos, E.M.; Duarte, E.A.; Prata, N.V. Cidadania e trabalhos na sociedade da informação: uma abordagem baseada na competência informacional. Perspectiva em Ciencia da Informação, v.13, n.3, p.208-222, 2008. Disponível em: <http:/ /portaldeperiodicos.eci.ufmg.br/index.php/pci/article/view/ 142/512>. Acesso em: 10 maio 2014.

Shera, J.H. Bibliographic management. In: Brenni, V.J. (Ed.). Essays on bibliography. Metuchen: Scarecrow, 1975.

Silva, T.E.; Tomaél, M.I. Fontes de informação na Internet: a literatura em evidência. In:Tomaél, M. I.; Valentim, M.L.P. (Org.). Avaliação de fontes de informação na internet. Londrina: EdUel, 2004. p.1-17.

Tomaél, M.I.; Alcará, A.R.; Silva, T.E. Fontes de informação na Internet: critérios de qualidade. In: Tomaél, M.I. (Org.). Fontes de informação na internet. Londrina: EdUel, 2008. p.3-28.

United States. Department of Labor. Bureau of labor statistics. Washington, 2014. Available from: <http://www.bls.gov/iag/ tgs/iag51.htm\#about>. Cited: May 4, 2014.

Valentim, M.L.P. A indústria da informação e os produtores de bases de dados em C\&T. Perspectiva em Ciência da Informação, v.7, n.1, p.23-37, 2002. Disponível em: <http://portalde periodicos.eci.ufmg.br/index.php/pci/article/view/411/224>. Acesso em: 10 maio 2014.

Zarifian, P. O modelo da competência: trajetória histórica, desafios atuais e propostas. São Paulo: Senac, 2003. 

